\title{
Graduate Student Retention of Prerequisite Course Content
}

Carol A. Tessel

Florida Atlantic University, ctessel@fau.edu

Vikas Grover

New York Medical College, vgrover2@nymc.edu

DOI: https://doi.org/10.30707/TLCSD4.1/ULMQ3912

Follow this and additional works at: https://ir.library.illinoisstate.edu/tlcsd

Part of the Speech Pathology and Audiology Commons

\section{Recommended Citation}

Tessel, Carol A. and Grover, Vikas (2020) "Graduate Student Retention of Prerequisite Course Content," Teaching and Learning in Communication Sciences \& Disorders: Vol. 4: Iss. 1, Article 1. DOI: https://doi.org/10.30707/TLCSD4.1/ULMQ3912

Available at: https://ir.library.illinoisstate.edu/tlcsd/vol4/iss1/1

This Scholarship of Teaching and Learning Research is brought to you for free and open access by ISU ReD: Research and eData. It has been accepted for inclusion in Teaching and Learning in Communication Sciences \& Disorders by an authorized editor of ISU ReD: Research and eData. For more information, please contact ISUReD@ilstu.edu. 


\title{
Graduate Student Retention of Prerequisite Course Content
}

\begin{abstract}
Although most graduate schools for Speech-Language Pathology require the same core prerequisite classes, there is still variation in class requirements as well as variation in course content. Sixty-one instructors completed a survey regarding what they felt was essential course content from their prerequisite communication sciences and disorders (CSD) classes. This information was used to create a student survey that consisted of 55 multiple choice questions chosen to assess knowledge from eight typically required prerequisite courses. Students preparing to enter their first year of their master's program were asked to take the survey. Instructors that reported teaching a course in audiology agreed the most on course content. Regarding the student survey, students performed best in the areas of audiology and anatomy and physiology. Students that had a more than two-year gap between undergraduate coursework and their graduate program start date performed significantly worse than those who had a less than two-year gap. The variables of undergraduate major, age, and type of university did not prove significant. Implications for instructors and course content are discussed.
\end{abstract}

\section{Keywords}

Graduate students, retention of course content 


\section{Introduction}

There are currently more than 250 graduate programs in the United States offering a degree in Speech-Language Pathology (American Speech-Language-Hearing Association [ASHA], n.d.); however, there is variation in prerequisite requirements and course content based on materials used and instructor preference. For example, some programs allow students to complete prerequisite requirements while enrolled in graduate programs, while others require all prerequisites completed prior to a master's program start date. A previous review of 12 graduate schools' (from unknown states) prerequisite requirements revealed a range of six to 12 classes being required before graduate school admittance (Lubinsky, 2004). A review of five of the Communication Sciences and Disorders (CSD) graduate program requirements in the state of Florida revealed a range of six to nine required classes. Not all schools required a prerequisite language disorders or introduction to communication disorders course. One out of the five schools had lab classes associated with its prerequisite courses. Notably, all universities required courses on language development, phonetics, anatomy and physiology, neurological basis of communication, speech science, and audiology/hearing. It was also notable that some graduate programs are requiring a 'boot camp' before students begin their graduate coursework. It is likely that many programs have noticed disparities in students' levels of knowledge retention and this may be the impetus for implementing the use of a boot camp. One school's boot camp was "designed to provide incoming first year Speech-Language Pathology graduate students with a framework and foundational knowledge which should translate to improved success as an MA level SLP student” (University of Florida Health, "2014 MA-SLP Bootcamp Complete”, 2014, para. 2)

During an undergraduate program, each undergraduate class instructor might use different assignment/exam formats to assess students' knowledge (e.g., multiple choice tests, essay tests, essay assignments, etc.). Research into graduate student knowledge has focused on specific content areas/special topics rather than a broad view of knowledge retention. For example, one study assessed undergraduate and graduate student knowledge of autism (Price, Roberts, Henderson, \& Kelley, 2009). Findings indicated that students had the most knowledge of diagnosis and intervention for clients with autism, but had less knowledge of the characteristics of autism and even less knowledge regarding the causes of autism (Price et al., 2009). Understanding the characteristics and causes of autism are fundamental to diagnosis and treatment and therefore a particular concern that this is the area most lacking. Findings such as these can be useful for instructors in gearing their lectures/class content to solidify the knowledge base in these areas of deficit.

Other studies have revealed students' limited knowledge of African American English (AAE) (Wilson Ottley \& Bland Stewart, 2010), difficulty identifying the major risk factors for stroke (Terry, Marshall, Lankford, Pittman, \& Ellis, 2008), students' ageist attitudes and limited knowledge of aging (Darling, 2016). As the aging population grows in the U.S., these areas of knowledge will continue to be more important and Speech-Language Pathology (SLP) instructors will have the task of ensuring that students leave school with a better understanding of aging and a less ageist attitude towards the aging populations' abilities. Students that are more open minded and have a better understanding of how diversity affects speech and language, will likely be more successful graduate students and future clinicians. 
Another area of interest in the field of SLP is the topic of online vs. traditional classroom learning. As of 2016, less than 3\% of undergraduate CSD programs offer an online option (Richards \& Fischer, 2017); however, the number of undergraduate students across majors taking at least one distance-learning course continues to increase (Babson, 2015). As this is a new phenomenon in our field, there is limited evidence to say whether taking classes online vs. in person for CSD topic areas would lead to better retention of information and in turn better performance in CSD graduate school. Historically, there is evidence that the medium of instruction is not as important as the method of instruction going back to the 1980's (Clark, 1994, Kulik \& Kulik, 1987, Russell, 1999, Wentling et al., 2000). Many studies have shown that multiple media types can be effective with strong instructional methods (see Mayer, 2003 for a review). In truth, the fact that e-learning is learner centered and self-paced may be an advantage with today's students, most of whom fit into the category of millennials (Zhang, Zhao, Zhou, \& Nunamaker, 2004). The responses to a survey completed by digital learners that fit the description of a millennial indicated that improved learning was correlated with flexibility, customized interaction, and proper usage of digital content (Nalini, Maragatham, Gayathri \& Dhivabharathi, 2018). Millennials are known to prefer a more hands on learning style with opportunity for experimentation and application (Rapillard, Plexico, \& Plumb, 2019). Although undergraduates may have more experience with technology and online learning, they also demonstrate less advanced critical thinking skills and more procrastination behavior, which could affect their learning (Artino \& Stephens, 2009).

The aim of the current study is to better understand exactly what knowledge is retained from prerequisite coursework, and which factors might affect a student's ability to retain this knowledge. Results could lead to a shift in graduate school requirements, inform instructors on changes needed to undergraduate curriculums, and enlighten graduate school instructors on which concepts from prerequisite courses may still require review at the graduate level.

Purpose. The purpose of this study was twofold. The first goal was to gain insight into which essential knowledge concepts would obtain agreement across undergraduate professors teaching prerequisite classes. The second goal was to assess the knowledge of incoming master's students in the field of SLP. As most graduate schools accept students from a variety of undergraduate programs, it's of vital importance to understand the content knowledge students have retained from their undergraduate coursework. Those areas that prove the most difficult may require a review or greater emphasis in graduate school. Having a better understanding of students' knowledge as they enter graduate school for CSD will not only help the instructors in gaining insight about the depth of incoming students' knowledge in various areas, but also allow the undergraduate instructors to tailor their courses to emphasize any information that does not appear to be retained by students. This is especially important in a profession where many people may be entering graduate school with an unrelated major and coming into the program with the required prerequisite classes for graduate school either as electives or as non-degree seeking students.

In order to achieve the objectives of the study, two surveys were disseminated. First, a survey was distributed to professors that teach undergraduate courses. They were asked to identify areas of essential knowledge from each class that they had experience teaching. A student survey in the form of a multiple-choice test was then created. The student survey covered essential 
knowledge concepts identified by respondents to the professor survey. The student survey allowed for evaluation of course knowledge retention based on age, area of undergraduate major, course format (online vs. in person), type of university, or the number of years between the completion of their undergraduate program and entering graduate school.

It was hypothesized that older, more mature students would perform better on a test assessing their knowledge of undergraduate concepts. Students of non-traditional age, specifically females, have shown more intrinsic motivation for class success and use certain cognitive strategies that indicate a more comprehension focused learning strategy more often than younger students (Justice \& Dornan, 2001). Those students whose major in college was CSD are also expected to perform better, as their electives may have been more speech and language related and their college experience may have included more SLP related extracurricular experiences that could have assisted in solidifying their knowledge base. Those students who finished their undergraduate coursework less than two years before beginning graduate school were expected to perform better than those who started graduate school more than two years after finishing their undergraduate coursework. As with the professor survey, student respondents were asked to identify the type of university they attended. This was done to ascertain whether there was a similar sampling of private vs. state (public) universities as there was with the professor survey, but a difference in performance based on university type was not expected. Regarding online vs. in person classes, as there has not been previous research into this area with CSD classes, the goal was simply to gain more knowledge about whether instructional medium had an effect on their ability to retain knowledge.

\section{Method}

Participants. Participants for both surveys were recruited online via the ASHA Special Interest Group (SIG) 10 community board or via email through social networks. The recruitment emails asked that professors complete the professor survey, or in the case of the student survey, that they pass the survey along to their students. Professors were specifically asked to participate if they were currently teaching or had taught prerequisite courses for CSD. Students were asked to participate only if they were about to start graduate school, but had not yet begun attending classes. As these surveys were disseminated online and via email, it was not possible to ascertain how many people (both professors and students) declined to participate.

Professor Survey. A survey was disseminated to CSD departments throughout the country. Dissemination was completed at both of the authors' universities, through the SIG 10 community board, as well as directly to the department chairs of a number of graduate programs. Some of these programs were chosen at random and others out of convenience and familiarity. Professors and instructors who currently teach or have taught undergraduate/prerequisite courses in CSD topics were asked to complete the survey $(N=61)$. Participants were asked which state they taught in and whether they taught in a private $(n=19)$ or state $(n=43)$ university, with one participant reporting they teach at both private and state universities.

The survey was intended to acquire information regarding which concepts these instructors considered essential from each of the eight courses examined. Professors were asked to check off which items they thought were essential knowledge after taking their courses (they were 
given 5-8 choices for each course topic area) and also asked to add any other information they felt was essential via open response. The responses provided by the survey were constructed by the authors (for the classes they had experience teaching). For classes that the authors did not have experience teaching, textbook reviews were completed from the corresponding undergraduate classes and consultation with professors who have experience teaching each class. The course areas were categorized as follows based on review of graduate program requirements across the country:

1. Audiological Sciences (Audio)

2. Language Development (LDev)

3. Language Disorders (LDis)

4. Introduction to Communication Disorders (ICD)

5. Speech Science/Acoustics (SSci)

6. Phonetics (Phon)

7. Anatomy and Physiology of the Speech Mechanism (A\&P)

8. Neurology/Neural Basis of Communication Disorders (Neuro)

Student Survey. After analysis of the professor survey was completed, the student survey was then disseminated again through the authors' universities, the ASHA SIG 10 community board, through social networks and directly to department chairs of familiar universities. Again, some of these programs were chosen at random and others out of convenience and familiarity. Professors and chairs were asked to send the recruitment email out to their students. As the survey was anonymous, the professors and chairs could not have known which students responded or declined to respond. This survey was available from August 8, 2018 until September 2, 2018. The survey was closed on Labor day as most programs in the country begin their classes after Labor Day and only students who had completed their prerequisite coursework, but not yet begun their graduate coursework, were asked to complete the survey ( $N$ $=63)$.

The student survey was created using the information provided by professors in the previous survey. In an effort to make the survey a reasonable length, not every possible topic could be covered in the student survey. The questions created were based on the responses that received the most positive feedback from professors (i.e., professors agreed that this was essential knowledge from that particular course) and the areas that were most often provided by participants (via open response) as additional essential information. For example, for the items pertaining to the anatomy and physiology class, 24 of the 25 respondents agreed that knowing the cartilages of the larynx was essential knowledge and at least six respondents added that understanding respiratory physiology (specifically Boyle's law) was essential knowledge. Therefore, questions regarding these two topics were included in the survey. Both authors as well as a graduate assistant wrote and reviewed the questions. An audiologist was consulted regarding the appropriateness of the audiology related questions and they were approved. Three different Speech-Language Pathologists were consulted regarding the appropriateness of the questions for the other seven class topic areas and changes were made after feedback was given. (See Appendices A \& B for complete professor and student surveys). 
Procedures. For both surveys, data were collected via Qualtrics, an online survey tool (Qualtrics, 2018). The Institutional Review Board for first author's institution approved the proposed study. Participants were asked to answer all questions but could skip any that they chose. They were not given feedback on their responses. The surveys were anonymous, as participants were not asked their names or other identifying information.

\section{Data Analysis}

Professor Survey. Researcher provided responses and participant provided responses were analyzed for the percentage of participants in agreement that these topics are essential knowledge for each given class. The participant provided responses were first categorized and grouped into larger topic areas to better analyze agreement. For example, for the neurology class, participants provided responses such as, neuronal physiology or neuron parts and function, hence these two and other similar responses were placed into a category termed, Neuronal Anatomy \& Physiology.

Student Survey. Questions 1-8 on this survey served to gain information regarding the planned independent variables. These included age at time of survey, undergraduate major, type of university (private or state), medium of courses taken (online vs. in person), and how many years since the person had taken their undergraduate coursework in CSD. Age at time of survey was split into three groups for the analysis, 23 years old or less, 24 to 28 years and over 28 years. The youngest group of students were unlikely to have any time gap between undergraduate and graduate programs. The second age group may have included students who were reapplying to graduate school, applying after spending a year or two taking prerequisites, or applying after working at a bachelor's level therapist or speech aide. The over 28 years old group was meant to encompass people who were at least five years out from finishing their bachelor's degree and had possibly five years of work experience in either related or unrelated fields. The dependent variable was students' accuracy on the 55 question general CSD knowledge survey. A series of comparisons were completed using the Mann-Whitney nonparametric alternatives to the $t$ test. As the sample comparisons were not normally distributed and some contained small $N$ 's, this was the most appropriate analysis option to assess for how well each of the independent variables predict the students' score (Hollingsworth, Collins, Smith, \& Nelson, 2011). A Kruskal-Wallace test was used for the one variable that had more than two categories (i.e., age). All tests were then subject to a Bonferroni correction, making $p$ values of more than .013 not significant.

As results were calculated, it became clear that one question (originally part of the ICD class questions) had multiple valid answers, therefore, that question was removed, leaving 54 questions in the analysis.

\section{Results}

Professor Survey. Sixty-one participants from 29 states completed the professor survey. Percent agreement was calculated for each researcher provided response in each topic area. For example, for the ICD class, most of the respondents agreed that Pragmatic aspects of communication (93\%) and The definition of a phoneme (86\%) were essential areas of knowledge 
after taking this class. The largest areas of participant given responses were under the topic areas of basic terminology and knowledge of speech-language pathology/audiology (9 responses) as well as typical language development (7 responses). (See Table 1 for agreement broken down by topic area and Table 2 for the top four participant provided response areas for each course.)

Table 1. Class/topic area and percent agreement based on the researcher provided responses.

\begin{tabular}{lccc}
\hline Topic Area & $\begin{array}{c}\text { Total } \\
\text { Responses }\end{array}$ & $\begin{array}{c}\text { \# Researcher } \\
\text { provided items }\end{array}$ & $\begin{array}{c}\text { Agreement } \\
\text { Mean }\end{array}$ \\
\hline Introduction to Communication Disorders & 28 & 8 & $68 \%$ \\
Language Disorders & 27 & 8 & $75 \%$ \\
Language Development & 30 & 5 & $87 \%$ \\
Neurological Basis & 12 & 8 & $74 \%$ \\
Anatomy \& Physiology & 25 & 7 & $84 \%$ \\
Audiology & 11 & 7 & $88 \%$ \\
Speech Science & 22 & 7 & $76 \%$ \\
Phonetics & 21 & 7 & $84 \%$ \\
\hline
\end{tabular}

Table 2. Top four participant-provided response categories for each course.

\begin{tabular}{ll}
\hline Course & Participant provided response topic areas \\
\hline ICD & Basic terms/knowledge, Typical development, Disorders, Impact of Disability \\
Ldis & $\begin{array}{l}\text { Language sample analysis, Disorders, Intervention, Assessment } \\
\text { Developmental milestones, Multicultural issues, Literacy, Theories of } \\
\text { development } \\
\text { Ldev }\end{array}$ \\
Neuronal anatomy, Sensory \& motor pathways, Neuron communication, \\
Neuro & Subcortical structures \\
A\&P & Respiratory A \& P, CNS/PNS, Articulatory A \& P, Phonatory A \& P \\
Audio & Otoscopy \& Tympanometry, Disorders, Hearing Screenings, Air \& bone \\
Ssci & conduction testing (practical skills) \\
Phon & Speech perception/processing, Wave properties, Spectrograms, Speech production \\
& Basic IPA, Dialectal differences, Coarticulation, Diacritics \\
\hline
\end{tabular}

Student Survey. The percent correct scores for all participants were analyzed for frequency, as well as skewness and kurtosis. Results revealed a skewness of -1.602 (SE = .309). Dividing the skewness by its standard error revealed a value of -5.18 , indicating that the data are not normally distributed. A histogram plot revealed an outlier with a score of $27 \%$. After this score was removed, the skewness was then valued at -.269 $(\mathrm{SE}=.311)$, representing a normally distributed data set. The new overall mean (excluding the outlier and 3 participants that did not complete at least 52 of the 54 questions) was $69 \%(\mathrm{SD}=10 \%)$. The mean and standard deviation of all independent variables can be seen in Figure 1. The outlier was removed from all following analyses. See Figure 1 for survey scores broken down by independent variable. 


\section{Independent Variables}

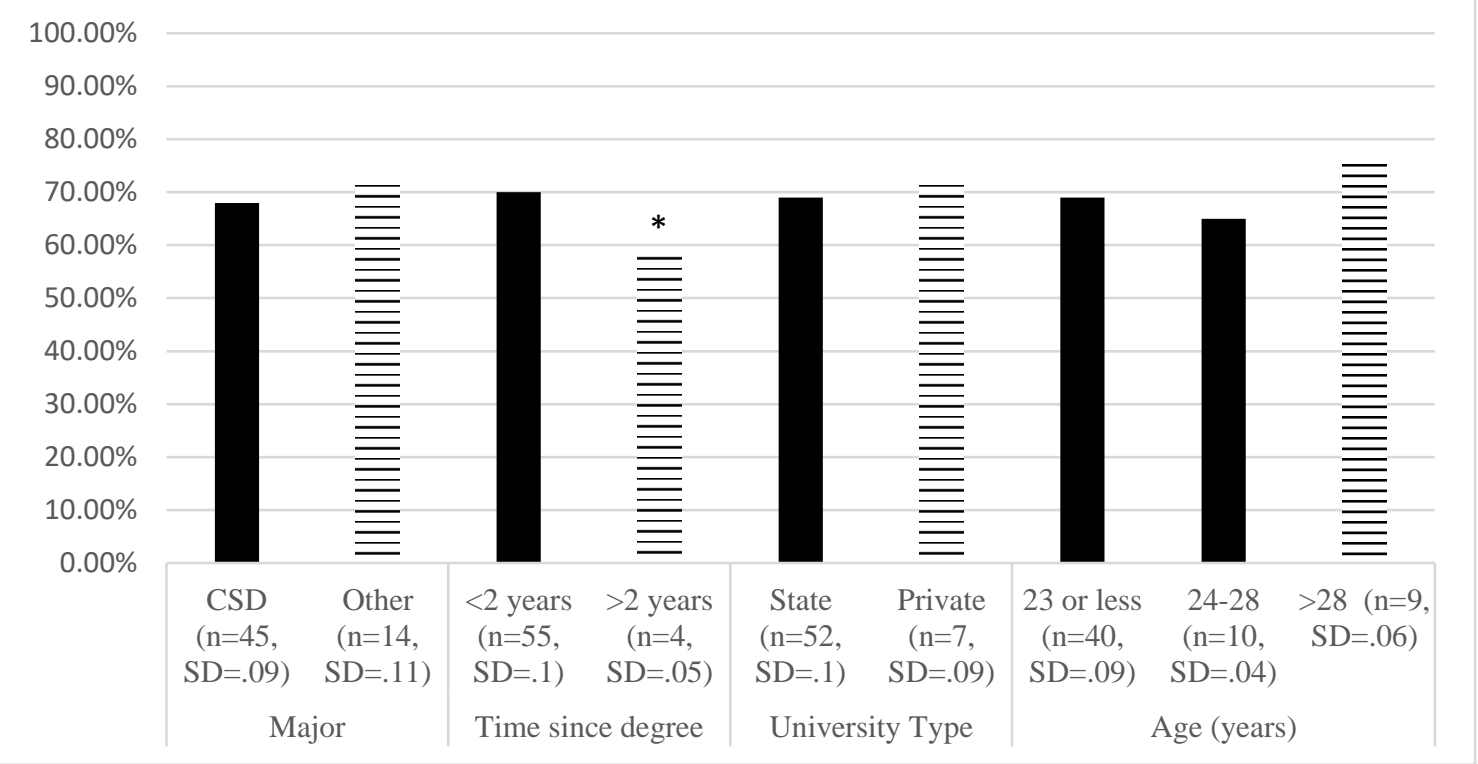

Figure 1. Survey scores broken down by independent variable/demographic information.

Note: Striped lines represent the less populated group. Asterisk represents a significant effect after Bonferroni correction $(p<.013)$.

In order to determine if those students whose undergraduate major was CSD performed better than those who had a different major, a Mann-Whitney test was utilized. Results revealed that test scores for those with a CSD major $(M d n=69 \%, n=45)$ and test scores of those with a different undergraduate major $(M d n=75 \%, n=14)$ did not differ significantly, $U=229, p=$ $.124, \eta^{2}=.041$.

A Mann-Whitney test was also used to determine if those who had taken their undergraduate courses more than two years before starting their graduate work performed better than those who started less than two years after completing their graduate work. The Mann-Whitney revealed that test scores were significantly higher for those who started graduate school less than two years after completing their undergraduate work $(M d n=70 \%, n=55)$ than for those who were starting graduate school more than two years after finishing their CSD coursework $(M d n=57 \%$, $n=4), U=28, p=.009, \eta^{2}=.106$.

A following Mann-Whitney test indicated that those students who attended private undergraduate universities $(M d n=72 \%, n=7)$ did not perform significantly better than those students that attended state universities $(M d n=69 \%, n=52), U=137, p=.304, \eta^{2}=.019$. To ascertain whether the age at which a person enters graduate school would affect their test score, a Kruskal-Wallis test was completed. The age variable was broken down into three categories, those 23 years old and under, 24 to 28 years of age, and over 28 years of age. The students in the 23 years and under category had a median score of $69 \%(n=40)$, the middle category had a median score of $64 \%(n=10)$, and the oldest group had a mean of $76 \%(n=9)$. Although the oldest group had higher scores on average, a Kruskal-Wallis $\mathrm{H}$ test revealed that 
there was not a statistically significant difference in scores based on age, $\chi^{2}(2)=5.334, p=$ 0.069 , with a mean rank score of 29.13 for the 23 and under group, a mean rank score of 23.5 for the middle group, and a mean rank score of 41.11 for the oldest group.

Each category of questions was then analyzed to assess whether there was a significant difference in test scores for a particular topic area (i.e., SSci, Ldis, etc.), when those that took a specific course online were compared to those that took it in person in a traditional setting. None of these tests revealed a difference in performance based on medium of the course $(p>.1$ in all cases). (See Table 3 for all results.)

Table 3: Mann-Whitney results by topic area for students taking classes online or in person.

\begin{tabular}{lccccc}
\hline & $\begin{array}{c}\text { Online } \\
\text { Median }(\boldsymbol{n})\end{array}$ & $\begin{array}{c}\text { Traditional } \\
\text { Median }(\boldsymbol{n})\end{array}$ & $\boldsymbol{U}$ value & $\boldsymbol{p}$ value (exact) & $\boldsymbol{\eta} 2$ \\
\hline Speech Science/Acoustics & $79(4)$ & $71(55)$ & 73.5 & 0.283 & 0.023 \\
Anatomy \& Physiology & $81(4)$ & $75(55)$ & 55.5 & 0.102 & 0.049 \\
Phonetics & $67(5)$ & $67(54)$ & 132.5 & 0.947 & $8.69 \mathrm{E}-05$ \\
Neuroanatomy & $67(6)$ & $67(53)$ & 153 & 0.893 & 0.0004 \\
Language Disorders & $83(2)$ & $78(57)$ & 26 & 0.229 & 0.031 \\
Language Development & $50(6)$ & $67(53)$ & 125 & 0.41 & 0.013 \\
Intro to Communication & $75(4)$ & $67(55)$ & 102 & 0.827 & 0.001 \\
Audiology/Hearing & $83(3)$ & $83(56)$ & 83 & 0.987 & $8.04 \mathrm{E}-07$ \\
\hline
\end{tabular}

Note: Median values are in percentages.

To assess for which topic area had information that was well retained by most of the students, the average scores for each course topic area was calculated. Course areas performed as follows from best to worst, Audio $(M=79 \%)$, A\&P $(M=72 \%)$, LDis $(M=70 \%)$, SSci $(M=71 \%)$, ICD \& Phon $(M=69 \%)$, Neuro $(M=64 \%)$, and $\operatorname{LDev}(M=56 \%)$. A discrimination index was completed using the top 15 performing participants and 15 lowest performing participants (Kelley, 1939). Results indicated that only three questions had negative values, and five had a value of zero, indicating that most questions did a good job of discriminating higher performing from lower performing test takers. (See Appendix C for difficulty and discrimination index results.)

A difficulty index was completed to assess for the percent of participants who answered each question correctly, as well as which alternate choices provided a plausible alternative to the correct answer. The Audio, Phon, and LDis courses had the most incorrect options providing a plausible answer for at least some of the respondents. Those questions where the majority of responses were an incorrect response were subject to closer inspection. Of the 54 questions in the analysis, there were six questions where the majority of participants answered with an incorrect answer. All of these six questions were from different topic areas For example, question \#14 from the SpSci topic area, The source filter theory describes the interaction between what two systems?, where $32 \%$ chose the correct answer (phonatory and articulatory) and $34 \%$ chose an incorrect choice (respiratory and phonatory). In this case, the split was almost even between the two most favored answers. However, question \#25 from the phonetics topic area, Which phoneme can never be in the final position of a word in English? had a much larger split, with only $32 \%$ of participants answering correctly $(/ \mathrm{w} /)$ and $63 \%$ choosing one of the incorrect choices $(/ 3 /)$. From the introduction to communication disorders class, the question 
Which item is NOT an aspect of pragmatic language development? was answered correctly (ability to use grammatically appropriate sentences) by only 5\% of respondents, while over $91 \%$ of respondents chose the incorrect answer (ability to imply implicit rules for interaction in different contexts). The other three incorrectly answered questions involved functions of cranial nerves, extension and expansion methods used in treatment, and pre-linguistic language milestones.

\section{Discussion}

The purpose of this study was to identify which topic areas appear to be the most challenging for undergraduate students to retain and understand as they enter graduate school. The results could potentially assist both undergraduate and graduate instructors on which topic areas may need reinforcement and/or more class time.

Professor Survey. The professor survey revealed that among those participants who responded to the Audiology questions, there was the most agreement as to which concepts should be taught in that class compared to the other classes. There was also at least $80 \%$ agreement among the professors that taught language development, phonetics, and anatomy and physiology. This suggests that these four classes may be taught in the most uniform manner across universities. The two classes with the least agreement were language disorders and introduction to communication disorders. Interestingly, these two classes are not always required prerequisite classes and many schools may have this content worked into their language development class. Based on responses, as well as review of a few textbooks used to teach introduction to communication disorders, this class may include more or less specific information regarding the scope of practice and responsibilities of a Speech-Language Pathologist.

Student Survey. Of all the eight class topic areas assessed in the student survey, participants performed the best on the Audiology related questions $(M=79 \%)$. Interestingly, Audiology was the class that had the most agreement $(88 \%)$ regarding essential elements for the class from the professor survey. It may be that this class is taught more uniformly than the others and therefore questions may have been better suited for students from different universities that took the survey exam. The phonetics and neuroanatomy classes had the worst response rates (67\%). It may be that these classes involve information that may not be as well incorporated into other classes and therefore students have not had as much chance to apply this knowledge in more than one class. In addition, IPA is often considered its own language and without practice it would not be uncommon for a student to lose their skills in this area. In addition, some instructors may teach this class using accurate transcription as the main goal without providing an element of speech science to assist in enhancing conceptualization. For example, it is possible that including things like spectrogram analysis and use of programs like Praat (Boersma \& Weenink, 2017), along with transcription may aid in knowledge retention. The neuroanatomy class often includes an emphasis on learning the place and function of each cranial nerve. This may require consistent practice and relevant context. Students may be memorizing instead of truly learning these concepts, therefore retention may vary. In addition, from the language development class, the concepts of extension and expansion as treatment methods proved difficult for the student participants. Although 19 of 27 professor respondents agreed that this was essential knowledge 
from this class, it may be that students have yet to fully grasp treatment methods or how they connect to different disorders.

Of the four independent variables that were planned for analysis, only the time gap between undergraduate classes and start of graduate school was significant. Those students who were starting graduate school more than two years after completion of their degree performed worse than the ones who had more recently taken their undergraduate prerequisites. This could in part be that they are simply forgetting the material over the years. Another possible explanation is that those students who had more than a two-year gap may be students who had to reapply for graduate school multiple times and therefore may be lower performing students in general. Results from this analysis should however be interpreted with caution, as the group of students who were starting graduate school more than two years post-graduation from a bachelor's program numbered only four, in comparison to the group of 55 students who had more recently received a degree. A larger study would be needed to confirm these results.

Although the relationship between age and score did not reach significance, an interesting trend was observed where those students who were over 28 performed better than both younger categories of students and those that were in the middle age group performed worse than both the younger and older group. Surprisingly, of the four students who were more than two years out of their undergraduate program, two were in the younger age group and two were in the oldest age group, indicating that the middle age group performing worse was not affected by students being more than two years out of undergraduate programs.

The variable of online vs. in person classes was not significant. This may be due to the small $N$ in the online groups. It may also be a product of variation in course interactivity and/or difficulty. It is also possible that as with other topic areas that have been researched in the past, CSD classes can be administered effectively through a variety of mediums without a cost to learner outcomes.

Integration of results across surveys. When integrating the answers from the professor survey and the results from the student survey there were a few findings that stood out. First, 20 of 22 participants that took the professor survey agreed that the source filter theory was an essential concept of the speech science/acoustics class; however, a question regarding this topic was answered correctly by only $34 \%$ of the student survey participants. Similarly, 15 of the 21 participants from the professor survey who responded to the Phonetics class questions agreed that understanding that $/ \mathrm{w} /$ cannot end a word in English was essential knowledge, nevertheless only $34 \%$ of respondents to the student survey were able to correctly answer a question regarding this topic. Although this may seem like a discrete area of knowledge, understanding the difference between a grapheme and a phoneme/IPA symbol are essential knowledge and are demonstrated through a student's ability to understand how $/ \mathrm{w} /$ (or any other symbol) functions as a grapheme or a phoneme in English. Just as understanding what constitutes each anatomical system and how that system contributes to speech production is also an essential concept for perspective graduate students and future SLPs to understand.

Student respondents also demonstrated difficulty answering a question that involved understanding which skills are included under the umbrella of pragmatic language. It's unclear if this topic simply wasn't covered in depth or that students were only understanding it at the 
surface level and assuming it only encompasses things like eye contact that are often discussed in relation to Autism. In order to answer the pragmatic language question you would have to have a more in depth understanding of the term. The question that involved the specific function of one of the cranial nerves was also difficult for student respondents. It is possible that students often memorize cranial nerve functions and may then not retain this information for the future if they did not truly understand the concept to begin with or utilize this knowledge in future coursework.

Limitations and Future Research Directions. The authors acknowledge some limitations in the study. Data were collected from less than 70 professors and less than 70 students; however, they were from a wide range of states and institutions. Although there was not an exact relationship between the number of programs in a state and the number of respondents from that state, there were more than one respondents from states with more than 10 undergraduate programs, such as California, New York, and Texas. For the professor survey, some topic areas may have had more detailed questions than others. Future research should address a larger group of professors and students and take note of the academic standing of students taking the survey to ascertain if the survey differentiates between higher and lower performing students. Understanding whether or not performance on this type of survey before graduate school could predict graduate student success could also be useful. If this type of survey predicts graduate school performance, schools may consider using a similar survey as part of their admissions criteria.

Implications and Conclusions. Recently, many schools have been instituting boot camps before their graduate students enter. It is likely these boot camps represent a desire to have a cohort that is caught up or on equal footing. The concepts that proved most difficult here (e.g., the source filter theory, details of IPA symbols, cranial nerves, etc.) may be essential topics for these boot camps, as they proved difficult for more than half of our participants. Instructors may also consider using more hands-on methods of teaching for these more difficult topics, as this has been reported as a preferred method of learning by millennials. Not having adequate knowledge of concepts, such as IPA symbols, would certainly affect a student's ability to perform in their articulation and phonology class as well as their early childhood language classes in graduate school. It might also affect these students' ability to accurately monitor future clients, write goals, and prepare therapy materials. Inadequate knowledge of cranial nerves would undoubtedly affect their performance in neurologically based graduate classes, such as motor speech disorders or adult language disorders, as well as affect their ability to understand and review medical charts in a hospital-based externship. Suggestions for improving undergraduate preparation include having more communication among undergraduate instructors regarding course content via more ASHA convention seminars devoted to undergraduate course instruction or expanding conversations on the SIG community boards regarding the content in all undergraduate classes. Consideration into making prerequisite requirements more uniform across programs might also be beneficial, although a clearer picture of the true issues would first need to be established through a larger scale study of level of entrance knowledge and its relation to graduate school success. A conversation could begin at the state level, perhaps at state speech and hearing association conferences. Programs would need to confer on common issues and work together to find solutions. Some type of boot camp or other review session before graduate school begins may also be beneficial in helping to refresh students' understanding of undergraduate course concepts and help them to better integrate their knowledge into their 
graduate courses. It would be helpful if programs already instituting these practices would share their knowledge of student success in reference to efforts made in refreshing essential concepts before graduate school classes begin.

\section{Disclosures}

The authors have no financial or non-financial disclosures to report.

\section{References}

American Speech-Language-Hearing Association (n.d.). Search Edfind [Webpage]. Retrieved from https://www.asha.org/edfind/results.aspx?area=SLP\&degree=MASTERS\&location=ALL

Artino Jr, A. R., \& Stephens, J. M. (2009). Academic motivation and self-regulation: A comparative analysis of undergraduate and graduate students learning online. The Internet and Higher Education, 12(3-4), 146-151.

Babson Survey Research Group. Babson Study: Distance education enrollment growth continues (2016). Retrieved from: https://onlinelearningconsortium.org//news_item/babson-studydistance-education-enrollment-growth-continues-2.

Boersma, P., \& Weenink, D. (2017). Praat. Doing phonetics by computer (Version 6.0.29).

Clark, R. E. (1994). Media will never influence learning. Educational technology research and development, 42(2), 21-29.

Darling, R. M. (2016). Knowledge of aging and attitudes toward older people by communication sciences and disorders students. Contemporary Issues in Communication Science and Disorders, 43, 50-63.

Hollingsworth, R. G., Collins, T. P., Smith, V. E., \& Nelson, S. C. (2011). Simple statistics for correlating survey responses. Journal of Extension, 49(5), 14-21.

Kelley, T. L. (1939). The selection of upper and lower groups for the validation of test items. Journal of Educational Psychology, 30(1), 17-24.

Kulik, J. A., \& Kulik, C. L. C. (1987). Review of recent research literature on computer-based instruction. Contemporary Educational Psychology, 12(3), 222-230.

Justice, E. M., \& Dornan, T. M. (2001). Metacognitive differences between traditional-age and nontraditional-age college students. Adult Education Quarterly, 51(3), 236-249.

Lubinsky, J. (2004). CSD Graduate Programs' Entrance Requirements for Students Without CSD Backgrounds. Perspectives on Issues in Higher Education, 7(2), 6-7.

Mayer, R. E. (2003). The promise of multimedia learning: using the same instructional design methods across different media. Learning and Instruction, 13(2), 125-139.

Nalini, R. A. D. R., Maragatham, B., Gayathri, G. R., \& Dhivabharathi, M. (2018). Perception of millennials towards digital learning. International Journal of Pure and Applied Mathematics, 119(7), 2553-2564.

Price, J. R., Roberts, E., Henderson, B., \& Kelley, M. (2009, November). Knowledge of Autism in Speech-Language Pathology Undergraduate and Graduate Students in Mississippi. Poster presented at the annual conference of the American Speech and Hearing Association. New Orleans, LO.

Qualtrics [Computer Survey Software]. (2018). Retrieved from https://www.qualtrics.com.

Rapillard, S., Plexico, L. W., \& Plumb, A. M. (2019). Influence of graduate Speech-Language Pathology student's learning style and coping strategies on training and 
development. Teaching and Learning in Communication Sciences \& Disorders, 3(1), 2. Retrieved from https://ir.library.illinoisstate.edu/tlcsd/vol3/iss1/2

Richards, M. \& Fischer, R. (2017, November). Developing Undergraduate CSD Curricula: Preparation of Future Professionals. Poster presented at the annual conference of the American Speech-Language-Hearing Association. Los Angeles, CA.

Russell, T. L. (Ed.) (1999). The no significant difference phenomenon: As reported in 355 research reports, summaries and papers. Raleigh, NC: North Carolina State University.

Terry, J., Marshall, K., Lankford, J., Pittman, A. \& Ellis, C. (2008, November). Stroke Knowledge Among Speech-Language Pathology Graduate Students. Poster presented at the annual conference of the American Speech-Language-Hearing Association. Chicago, IL.

University of Florida Health. (2014, August 292014 MA-SLP Bootcamp Complete). Retrieved from https://slhs.phhp.ufl.edu/2014/08/29/2014-ma-slp-bootcamp-complete/.

Wentling, T. L., Waight, C., Gallaher, J., La Fleur, J., Wang, C., \& Kanfer, A. (2000). Elearning: A review of literature. University of Illinois at Urbana-Champaign: Knowledge and Learning Systems Group. Retrieved from https://pdfs.semanticscholar.org/5443/6f2ce08a83fb5f14f523e79b65b8a2c2f708.pdf.

Wilson Ottley, S. \& Bland Stewart, L. (2010, November). Speech-Language Pathology (SLP) Graduate Students' Knowledge of \& Experience with African-American English (AAE). Poster presented at the annual conference of the American Speech-Language-Hearing Association, Philadelphia, PA.

Zhang, D., Zhao, J. L., Zhou, L., \& Nunamaker, J. F., Jr. (2004). Can e-learning replace classroom learning?. Communications of the ACM, 47(5), 75-79. 


\section{Appendix A \\ Professor survey}

\section{I agree (1)}

I don't agree (2)

Q1 In what state do you teach?

Q2 Do you teach at a state or private university?

Q3 The following questions will be about the undergraduate courses that you teach. Do you or have you taught a class on Phonetics/IPA?

Yes (1)

No (2)

Q4 If you answered yes to the previous question please answer this question and the following one. Which of these concepts do you think a student should have adequate knowledge of after leaving your class?

The 'sh' sound in English is a single phoneme (1)

The 'th' sound in English is a single phoneme (2)

The /w/ sound cannot take final position in a word in English (3)

Be able to identify words that contain an affricate sound (4)

Be able to identify words that contain consonant clusters (5)

Be able to identify developmental processes such as fronting, stopping, and gliding (6)

The ability to count phonemes and morphemes in a word (7)

Q5 Besides the concepts listed above, what other concepts would say are equally important and expected to be understood by someone receiving a passing grade in your class?

Q6 Do you or have you taught a class in speech and hearing science/acoustics?

Yes (1)

No (2) 
Q7 If you answered yes to the previous question please answer this question and the following one. Which of these concepts do you think a student should have adequate knowledge of after leaving your class?

That the source filter theory describes the interaction between the human respiratory and phonatory systems (1)

Vocal pitch is determined by the size of a person's laryngeal structures (2)

Word stress is indicated by increases in pitch, duration, and loudness (3)

The inner ear contains the cochlea (4)

Binaural hearing is essential for sound localization (5)

The tongue is the major articulator for the production of vowels (6)

Pitch is the psychological correlate of frequency (7)

Q8 Besides the concepts listed above, what other concepts would say are equally important and expected to be understood by someone receiving a passing grade in your class?

Q9 Do you or have you ever taught a class in language development?

Yes (1)

No (2)

Q10 If you answered yes to the previous question please answer this question and the following one. Which of these concepts do you think a student should have adequate knowledge of after leaving your class?

At what age do children begin to babble (1)

At what age are children expected to have a vocabulary of 50-100 words (2)

What is an example of a complex sentence (3)

What is an example of an auxiliary verb (4)

Be able to calculate the MLU of a sentence (5)

Know the definition of pragmatics (6)

Q11 Besides the concepts listed above, what other concepts would say are equally important and expected to be understood by someone receiving a passing grade in your class? 
Q12 Do you or have you ever taught a class in audiological sciences?

Yes (1)

No (2)

Q13

If you answered yes to the previous question please answer this question and the following one. Which of these concepts do you think a student should have adequate knowledge of after leaving your class?

What are bone and air conduction testing used for (1)

What are otoacoustic emissions (2)

Distinctive characteristics of conductive vs. sensorineural hearing loss (3)

How to appropriately choose the appropriate form of hearing testing to use with a given patient (4)

An understanding of the social and vocational problems caused by hearing loss (5)

What is masking and what is it used for? (6)

What is ABR and what is it used for? (7)

Q14 Besides the concepts listed above, what other concepts would say are equally important and expected to be understood by someone receiving a passing grade in your class?

Q15 Do you or have you ever taught a course in Anatomy and Physiology of the speech and hearing mechanisms?

Yes (1)

No (2)

Q16

If you answered yes to the previous question please answer this question and the following one. Which of these concepts do you think a student should have adequate knowledge of after leaving your class?

The cartilages of the larynx and their placement (1)

The direction of movement of the diaphragm during inhalation (2)

Anatomical differences and challenges associated with a cleft palate (3)

The function of the cricothyroid muscle (4)

The location and names of the four lobes of the brain (5) 
What is the significance of Broca's area and where is it located? (6)

Where is the zygomatic bone located? (7)

Q17 Besides the concepts listed above, what other concepts would say are equally important and expected to be understood by someone receiving a passing grade in your class?

Q18 Do you or have you ever taught a class in neuroanatomy/neural basis of speech?

Yes (1)

No (2)

Q19 If you answered yes to the previous question please answer this question and following one. Which of these concepts do you think a student should have adequate knowledge of after leaving your class?

What structures make up the CNS and PNS? (1)

The difference between ipsilateral and contralateral (2)

What importance does the cerebellum have for motor activity? (3)

What are the major symptoms of a right hemisphere stroke? (4)

What are the major symptoms of Parkinson's disease (5)

What motor innervation is each cranial nerve responsible for? (6)

What is hydrocephalus and how does it occur? (7)

What is aphasia and where are the major regions of brain damage associated with it? (8)

Q20 Besides the concepts listed above, what other concepts would say are equally important and expected to be understood by someone receiving a passing grade in your class?

Q21 Do you or have you ever taught a class in language disorders?

Yes (1)

No (2)

Q22 If you answered yes to the previous question please answer this question and the following one. Which of these concepts to you think a student should have adequate knowledge of after leaving your class?

Use of expansion and extensions in treatment (1)

What is an IEP and what is our role (2) 
What is SLI and how is it diagnosed (3)

Genetic causes of language delays (4)

Understand the functional communication approach to treatment (5)

Causes and characteristics of children with autism spectrum disorder (6)

Assessment and diagnosis of children on the autism spectrum (7)

Phonological awareness and its role in early literacy (8)

Q23 Besides the concepts listed above, what other concepts would say are equally important and expected to be understood by someone receiving a passing grade in your class?

Q25 Have you ever taught an Intro to communication class?

Yes (1)

No (2)

Q26 If you answered yes to the previous question please answer this question and the following one. Which of these concepts do you think a student should have adequate knowledge of after leaving your class?

How nonverbal communication is used (1)

Intercultural communication issues (2)

Issues of gender in communication (3)

What is aphasia and how is it classified (4)

The SLPs role in reading/literacy issues (5)

The definition of phoneme (6)

Pragmatic aspects of communication (7)

Voice disorders and how they are classified (8)

Q27 Besides the concepts listed above, what other concepts would say are equally important and expected to be understood by someone receiving a passing grade in your class?

Q28 Do you teach any other courses whose content are not addressed in this study? If yes, please indicate the class below. 


\section{Appendix B}

Student Survey Questions

\section{I agree (1)}

I do not agree (2)

Q2

Did you attend college at a private or state school?

Private (1)

\section{State/City (2)}

Q3 Please indicate your undergraduate major

Communication sciences/speech pathology/speech and hearing sciences (1)

Other (2)

Q4

Are you entering graduate school more than 2 years since you took your last speech pathology related undergraduate class?

Yes (1)

No (2)

Q5 Please indicate your age

20-23 years (1)

24-28 years (2)

$28-32(3)$

$32+(4)$

Q6 Did you take any of your speech pathology related classes online?

Yes (1)

No (2)

Q7

If you answered yes to the previous question, please indicate which classes you took online.

Speech science/acoustics (1)

Hearing science/audiology (2) 
Language development (3)

Language disorders (4)

Introduction to communication (5)

Anatomy and physiology of the speech mechanism (6)

Neuroanatomy for speech pathology (7)

Phonetics (8)

Q8 The following questions will test your knowledge of what you learned in your undergraduate/prerequisite classes. Bone conduction testing bypasses hearing function of the ?

Outer ear (1)

Middle ear (2)

Inner ear (3)

Both a \& b (4)

Q9 Otoacoustic emissions (OAEs) measure?

Type of hearing loss (1)

Degree of hearing loss (2)

Function of the cochlea (3)

Acoustic reflex (4)

Q10 Someone with poor middle ear function but normal inner ear function would have which type of hearing loss?

Sensorineural hearing loss (1)

Conductive hearing loss (2)

Mixed hearing loss (3)

Noise-induced hearing loss (4)

Q11 What is masking used for during a hearing evaluation?

To ensure the sound is heard by the ear being tested, not the non-test ear (1)

To determine the type of hearing loss (2) 
To determine the hearing level using bone conduction (3)

To measure acoustic reflex (4)

Q12 Which hearing test records brain wave activity in response to sound?

Otoacoustic Emissions (OAEs) (1)

Auditory Brainstem response (ABRs) (2)

Pure tone testing (3)

Tympanometry (4)

Q13 Impacted cerumen is observed using which type of hearing examination?

Tympanometry (1)

Pure tone average (2)

Otoacoustic Emissions (3)

Otoscopy (4)

Q14 The source filter theory describes the interaction between what two systems?

Respiratory and articulatory (1)

Respiratory and phonatory (2)

Phonatory and articulatory (3)

Phonatory and neurological (4)

Q15 The psychological correlates of frequency and intensity are:

Pitch and amplitude (1)

Loudness and phase (2)

Pitch and loudness (3)

Pitch and vibration (4)

Q16 In English, word stress is indicated by changes in what three properties of speech?

Pitch, loudness, and duration (1)

Pitch, duration, and direction (2)

Timbre, duration, and intensity (3) 
Loudness, echo, and direction (4)

Q17 The most important articulator for vowels is:

The soft palate (1)

The hard palate (2)

The tongue (3)

The lips (4)

Q18 Sound waves can be measured using all but which measurement?

Phase (1)

Frequency (2)

Period (3)

Timbre (4)

Q19 Which of the following could be a set of harmonic values?

$150,300,400,500(1)$

$200,400,600,800(2)$

$120,140,160,180(3)$

$200,300,600,750(4)$

Q20 Boyle's law states that the absolute and of a gas are inversely proportional. (fill in the blanks)

Volume/velocity (1)

Volume/mass (2)

Velocity/temperature (3)

Volume/pressure (4)

Q21 Which of the following word sets both contain an affricate sound?

Jump, shut (1)

George, cheese (2)

Cheese, vision (3) 
Jester, push (4)

Q22 Which of the following word sets both contain a consonant cluster?

Shut, stop (1)

Flight, cheese (2)

Jump, shoot (3)

Smack, drum (4)

Q23 Which of the following words contains only 3 phonemes?

Pats (1)

Flight (2)

Thick (3)

Smack (4)

Q24 Which choice has the words that and measure correctly transcribed?

ðæt mezə (1)

ðæt mesə (2)

$\theta æ t$ mezə (3)

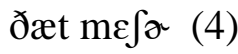

Q25 Which phoneme can never be in the final position of a word in English?

$/ \mathrm{m} /(1)$

/w/ (2)

/1/ (3)

/3/ (4)

Q26 In which case is a diacritic mark used correctly?

mæ̃n (1)

bæ $\theta(2)$

$\mathrm{s}^{\mathrm{w}} \mathrm{kil}(3)$

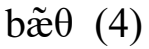


Q27 Which cartilage is the inferior most cartilage of the larynx?

Thyroid (1)

Cricoid (2)

Cuneiform (3)

Arytenoid (4)

Q28 During swallowing, the airway is covered and protected by the__?

Tongue (1)

Arytenoid (2)

Pyriform sinus (3)

Epiglottis (4)

Q29 Which statement is correct regarding inhalation?

The diaphragm moves downwards during speech breathing (1)

The diaphragm does not move during restful breathing (2)

The diaphragm moves upwards during speech breathing (3)

The diaphragm moves upwards during restful breathing only (4)

Q30 Which correctly identifies the 4 lobes of the brain?

Parietal, temporal, frontal, posterior (1)

Parietal, Temporal, Insular, Frontal (2)

Parietal, Temporal, Cerebellar, Occipital (3)

Parietal, Temporal, Frontal, Occipital (4)

Q31 The cricothyroid muscle is the major muscle used for what function?

Loudness adjustments (1)

Pitch adjustments (2)

Lowering of the larynx (3)

Relaxation of the vocal folds (4) 
Q32 The bone that houses the hearing mechanism is the?

Temporal (1)

Maxilla (2)

Zygomatic (3)

Ethmoid (4)

Q33 Which of the following is true of Broca's area?

It is located in the parietal lobe and is responsible for speech production (1)

It is located in the temporal lobe and is responsible for speech perception (2)

It is located in the frontal lobe and responsible for speech production (3)

It is located in the frontal lobe and responsible for speech perception (4)

Q34 The orbicularis oris would assist in production of which sounds?

$/ \mathrm{m} /$ and $/ \mathrm{b} /(1)$

$/ \mathrm{m} /$ and $/ \mathrm{d} /(2)$

/w/ and /d/ (3)

$/ \mathrm{n} /$ and $/ \mathrm{b} /(4)$

Q35 Which of these is a component of the Peripheral Nervous System (PNS)?

Nerves of the cerebellum (1)

Nerves of the larynx (2)

Nerves of the spinal cord (3)

Nerves of the cerebrum (4)

Q36 Which part of the brain is responsible for making our voluntary movements smooth and balanced?

Brainstem (1)

Temporal lobe (2)

Midbrain (3)

Cerebellum (4) 
Q37 Which of the following is true?

Damage to the left frontal lobe causes ipsilateral paralysis (1)

Damage to the left frontal lobe causes contralateral paralysis (2)

Damage to upper motor neurons will cause ipsilateral deficits (3)

Damage to lower motor neurons will cause contralateral deficits (4)

Q38 Which of the following is true?

The glosspharyngeal nerve innervates muscles of the tongue (1)

The vagus nerve innervates facial muscles (2)

The trigeminal nerve innervates muscles of mastication (3)

The oculomotor nerve assists in movement of the lips (4)

Q39

Which is not a part of a neuron?

Axon (1)

Dendrite (2)

Soma (3)

Bulb (4)

Q40

Which of the following is true of sensory nerves?

They have efferent fibers (1)

They bring impulses from the periphery to the CNS (2)

They are considered descending (3)

They bring impulses from the CNS to the periphery (4)

Q41 Which of the following is true of a diagnosis of SLI/DLD?

The student has language difficulties due to a hearing loss (1)

The student has language difficulties that interfere with academic function (2)

The student has language difficulties due to a diagnosed psychiatric disorder (3) 
The student has language difficulties that interfere with their ability to attend a gifted classroom (4)

Q42 Which of the following is NOT an activity to work on phonological awareness?

Blending of phonemes (1)

Segmentation of syllables in a word (2)

Rhyming (3)

Definitions of multiple meaning words (4)

Q43 Which of the following are NOT speech and language issues specifically related to autism?

Difficulty recognizing the need for clarification (1)

Understanding other's perspective (2)

Demonstrating a poor vocabulary (3)

Understanding facial expression (4)

Q44 Which of the following is true for an IEP given a diagnosis and parental consent:

Anyone who works with a child can write an IEP (1)

An IEP is required by law (2)

Development of an IEP is an option (3)

Parents cannot have any say in IEP goals (4)

Q45 A Language sample can provide us information about (Choose all that apply):

Use of gestures (1)

Structural complexity (Brown's stages) (2)

Use of eye contact (3)

Utterance length (4)

Q46 If a child says, "daddy car" and the parent says, "yes, that's daddy's car", "It is a big car"; it is an example of the following strategy:

Extension (1)

Expansion (2) 
Prompting (3)

Scaffolding (4)

Q47 Which of these would be good additions to functional communication goals for a non-verbal child?

Learning the sign for 'telephone' and the sign for 'daddy' (1)

Learning how to wink and how to shake head for 'no' (2)

Learning to shake head for 'no' and point to request (3)

Learning the sign for 'please' and signs for farm animals (4)

Q48 Which item is NOT an aspect of pragmatic language development?

Ability to communicate for a variety of purposes (1)

Ability to interpret social meaning from language (2)

Ability to use grammatically appropriate sentences (4)

Ability to imply implicit rules for interaction in different contexts (3)

Q49 Which one is the correct definition of a 'phoneme'?

Helps govern the rules of word organization in sentences (1)

A perceptually distinct unit of sound in a specific language (2)

Smallest unit of language that carries meaning (3)

The study of the system of sounds (4)

Q50 Which of the following is NOT part of aphasia classification?

Site of lesion (1)

Impact on speech fluency (2)

Impact on language comprehension (3)

Age of the client at time of injury (4)

Q51 Which of these items would be considered nonverbal communication?

Head nodding (1) 
Eye contact (2)

Touching the communication partner (3)

All of the above (4)

Q52 Which of the following both represent items within the scope of practice of an SLP?

Referral and diagnosis (1)

Language Assessment and Collaboration (2)

Balance Assessment and referral (3)

A \& B (4)

Q53 Which of the following are a possible causes of voice disorders (choose all that apply)?

Cancer (1)

Overuse (2)

Autism (3)

Injury (4)

Q54 Which of the following might be indicative of a communication disorder rather than a cultural difference?

A bilingual 2 year old that often code switches (1)

A bilingual 2 year old that has only 10 words in one language (2)

A 4 year old child who still drinks from a bottle (3)

A 3 year old that does not respond to their name (4)

Q55 When discussing form, content and use, which of following areas of language would fit under form?

Pragmatics (1)

Semantics (2)

Phonology and Syntax (3)

Syntax and Semantics (4) 
Q56 How many morphemes are in the following sentence? She's studying for her exams tonight.

$7(1)$

$8(2)$

9 (3)

$10(4)$

Q57 If the weather is nice today, we will go to the pool. This is an example of:

A simple sentence (1)

An interrogative sentence (2)

A complex sentence (4)

A compound sentence (5)

Q58 Which of the following sentences does NOT contain an auxiliary verb?

Do you want to eat lunch? (1)

I eat lunch at noon every day (2)

He has already eaten lunch (3)

Will you be eating lunch soon? (4)

Q59

At what age do babies typically begin to babble?

6-8 months (1)

8-10 months (2)

4-6 months (4)

10-12 months (5)

Q60 At what age are children expected to have a vocabulary of 50-100 words?

10-12 months (1)

12-14 months (2)

18-20 months (3)

24-26 months (4) 
Q61

Which of the following disorders would be associated with muscle weakness?

Apraxia (1)

Aphasia (2)

Dysarthria (3)

A lisp (4)

Q62 Which of the following would be considered a method of Augmentative and Alternative Communication (AAC)? (Choose all that apply)

Pen and paper (1)

Gestures (2)

Speech-generating device (3)

Sign language (4) 


\section{Appendix C}

Difficulty index per question $\&$ answer option and discrimination index per question.

\begin{tabular}{|c|c|c|c|c|c|c|}
\hline Question & $\begin{array}{l}\text { Difficulty } \\
\text { Index }\end{array}$ & Answer 2 & Answer 3 & Answer 4 & $\begin{array}{l}\text { Discrimination } \\
\text { index }\end{array}$ & Course \\
\hline 8 & $71.19 \%$ & $15.25 \%$ & $6.78 \%$ & $6.78 \%$ & 0.5 & Audio \\
\hline 9 & $52.54 \%$ & $23.73 \%$ & $18.64 \%$ & $5.08 \%$ & -0.06 & Audio \\
\hline 10 & $84.74 \%$ & $6.78 \%$ & $6.78 \%$ & $1.69 \%$ & 0.31 & Audio \\
\hline 11 & $100.00 \%$ & $0.00 \%$ & $0.00 \%$ & $0.00 \%$ & 0.06 & Audio \\
\hline 12 & $94.91 \%$ & $1.69 \%$ & $1.69 \%$ & $1.69 \%$ & 0.25 & Audio \\
\hline 13 & $79.66 \%$ & $13.56 \%$ & $5.08 \%$ & $1.69 \%$ & 0.13 & SpSci \\
\hline 14 & $33.89 \%$ & $35.59 \%$ & $18.64 \%$ & $11.86 \%$ & 0.06 & SpSci \\
\hline 15 & $72.88 \%$ & $23.73 \%$ & $1.69 \%$ & $1.69 \%$ & 0.25 & SpSci \\
\hline 16 & $91.53 \%$ & $6.78 \%$ & $1.69 \%$ & $0.00 \%$ & 0.25 & SpSci \\
\hline 17 & $61.02 \%$ & $23.73 \%$ & $13.56 \%$ & $1.69 \%$ & 0.19 & SpSci \\
\hline 18 & $81.36 \%$ & $16.95 \%$ & $1.69 \%$ & $0.00 \%$ & 0 & SpSci \\
\hline 19 & $81.03 \%$ & $12.07 \%$ & $6.90 \%$ & $0.00 \%$ & 0.13 & SpSci \\
\hline 20 & $81.36 \%$ & $10.17 \%$ & $8.47 \%$ & $0.00 \%$ & 0.31 & SpSci \\
\hline 21 & $72.41 \%$ & $17.24 \%$ & $6.90 \%$ & $3.45 \%$ & 0.19 & Phon \\
\hline 22 & $96.55 \%$ & $1.72 \%$ & $1.72 \%$ & $0.00 \%$ & 0.06 & Phon \\
\hline 23 & $94.92 \%$ & $3.39 \%$ & $1.69 \%$ & $0.00 \%$ & 0.13 & Phon \\
\hline 24 & $79.67 \%$ & $13.56 \%$ & $6.78 \%$ & $0.00 \%$ & 0.31 & Phon \\
\hline 25 & $33.89 \%$ & $62.71 \%$ & $3.39 \%$ & $0.00 \%$ & 0.06 & Phon \\
\hline 26 & $43.10 \%$ & $22.41 \%$ & $17.24 \%$ & $17.24 \%$ & 0 & Phon \\
\hline 27 & $45.76 \%$ & $27.12 \%$ & $18.64 \%$ & $8.47 \%$ & 0.31 & $A \& P$ \\
\hline 28 & $98.31 \%$ & $1.69 \%$ & $0.00 \%$ & $0.00 \%$ & 0.06 & A\&P \\
\hline 29 & $61.02 \%$ & $32.20 \%$ & $5.08 \%$ & $1.69 \%$ & 0.31 & $A \& P$ \\
\hline 30 & $96.61 \%$ & $1.69 \%$ & $1.69 \%$ & $0.00 \%$ & 0.06 & $A \& P$ \\
\hline 31 & $49.15 \%$ & $37.29 \%$ & $11.86 \%$ & $1.69 \%$ & 0.44 & $A \& P$ \\
\hline 32 & $76.27 \%$ & $15.25 \%$ & $6.78 \%$ & $1.69 \%$ & 0.31 & $A \& P$ \\
\hline 33 & $69.49 \%$ & $18.64 \%$ & $6.78 \%$ & $5.08 \%$ & 0.31 & $A \& P$ \\
\hline 34 & $84.75 \%$ & $11.86 \%$ & $3.39 \%$ & $0.00 \%$ & 0 & $A \& P$ \\
\hline 35 & $49.15 \%$ & $44.07 \%$ & $5.08 \%$ & $1.69 \%$ & 0.44 & Neuro \\
\hline 36 & $83.05 \%$ & $11.86 \%$ & $3.39 \%$ & $1.69 \%$ & 0.06 & Neuro \\
\hline 37 & $50.85 \%$ & $27.12 \%$ & $18.64 \%$ & $3.39 \%$ & 0.63 & Neuro \\
\hline 38 & $28.07 \%$ & $49.12 \%$ & $18.64 \%$ & $3.39 \%$ & 0.25 & Neuro \\
\hline 39 & $91.53 \%$ & $6.78 \%$ & $1.69 \%$ & $0.00 \%$ & 0.13 & Neuro \\
\hline 40 & $77.97 \%$ & $10.17 \%$ & $6.78 \%$ & $5.08 \%$ & 0.19 & Neuro \\
\hline 41 & $82.14 \%$ & $8.93 \%$ & $5.08 \%$ & $3.39 \%$ & 0.25 & Ldis \\
\hline 42 & $94.92 \%$ & $3.39 \%$ & $1.69 \%$ & $0.00 \%$ & 0.06 & Ldis \\
\hline 43 & $71.19 \%$ & $18.64 \%$ & $8.47 \%$ & $1.69 \%$ & 0.13 & Ldis \\
\hline
\end{tabular}


Tessel and Grover: Graduate Student Retention

\begin{tabular}{ccccccc}
44 & $82.76 \%$ & $10.34 \%$ & $6.90 \%$ & $0.00 \%$ & 0.19 & Ldis \\
45 & $43.10 \%$ & $22.41 \%$ & $13.56 \%$ & $24.14 \%$ & 0.19 & Ldis \\
46 & $15.25 \%$ & $67.80 \%$ & $15.25 \%$ & $0.00 \%$ & 0.13 & Ldis \\
47 & $86.44 \%$ & $8.47 \%$ & $5.08 \%$ & $0.00 \%$ & 0.25 & Ldis \\
48 & $5.17 \%$ & $91.14 \%$ & $3.39 \%$ & $0.00 \%$ & 0.06 & ICD \\
49 & $61.02 \%$ & $33.90 \%$ & $3.39 \%$ & $1.69 \%$ & 0.06 & ICD \\
50 & $79.66 \%$ & $11.86 \%$ & $6.78 \%$ & $1.69 \%$ & 0.44 & ICD \\
51 & $98.31 \%$ & $1.69 \%$ & $0.00 \%$ & $0.00 \%$ & 0 & ICD \\
52 & $94.92 \%$ & $5.08 \%$ & $0.00 \%$ & $0.00 \%$ & 0.06 & ICD \\
53 & $76.27 \%$ & $13.56 \%$ & $3.39 \%$ & $1.69 \%$ & 0.13 & ICD \\
54 & $74.58 \%$ & $22.03 \%$ & $3.39 \%$ & $1.69 \%$ & 0.38 & Ldis \\
55 & $71.19 \%$ & $20.33 \%$ & $6.78 \%$ & $1.69 \%$ & 0.06 & Ldev \\
56 & $71.19 \%$ & $22.03 \%$ & $3.39 \%$ & $3.39 \%$ & 0.19 & Ldev \\
57 & $50.85 \%$ & $44.07 \%$ & $3.39 \%$ & $1.69 \%$ & 0.06 & Ldev \\
58 & $57.63 \%$ & $23.73 \%$ & $11.86 \%$ & $6.78 \%$ & 0 & Ldev \\
59 & $38.98 \%$ & $50.85 \%$ & $8.47 \%$ & $1.69 \%$ & -0.31 & Ldev \\
60 & $46.43 \%$ & $42.86 \%$ & $8.47 \%$ & $0.00 \%$ & -0.13 & Ldev \\
61 & $88.14 \%$ & $8.47 \%$ & $3.39 \%$ & $0.00 \%$ & 0.06 & Ldis \\
\hline
\end{tabular}

